\title{
Occurrence, profile and possible sources of PCNs in Hong Kong soils, and a comparison with PCBs, PCDDs and PCDFs
}

\author{
Guorui Liu $\cdot$ Minghui Zheng $\cdot$ Zongwei Cai
}

Received: 4 April 2014 / Accepted: 24 June 2014 /Published online: 5 July 2014

(C) Springer-Verlag Berlin Heidelberg 2014

\begin{abstract}
Polychlorinated naphthalenes (PCNs) have been proposed for inclusion in the annexes of the Stockholm Convention by the European Union, signifying a probable increase in monitoring PCN levels at a global level. Investigations on PCN levels in the environment of Hong Kong have not been reported. In this preliminary investigation, PCN levels in surface soils samples were determined by isotope dilution HRGC/HRMS techniques, and compared with those of polychlorinated biphenyl (PCBs), polychlorinated dibenzo- $p$-dioxins (PCDDs) and dibenzofurans (PCDFs). The concentrations of PCNs in the soil samples were 35-883 $\mathrm{pg} \mathrm{g}^{-1}$ (average, 201; and median, $94 \mathrm{pg} \mathrm{g}^{-1}$ ), which were lower than those of PCBs PCDDs and PCDFs. This comparison suggested that PCNs are currently not priority POPs compared with dioxins and PCBs in Hong Kong soils. PCDDs were the most important contributor to the sum of toxic equivalents of PCNs, PCBs, PCDDs and PCDFs. OCDD was the most dominant dioxin congener in Hong Kong surface soils. PCB-118 was the most abundant in 12 dl-PCB congeners. PCN congeners indicating thermal related sources (CN52/60, CN66/67 and CN73) were relatively abundant in their respective homologs, which suggested PCN contamination from thermal sources. The ratio of CN73 to CN74 in soil samples suggested the contribution of PCN
\end{abstract}

Responsible editor: Leif Kronberg

G. Liu $\cdot$ Z. Cai $(\bowtie)$

Department of Chemistry, Hong Kong Baptist University, Kowloon Tong, Kowloon, Hong Kong, SAR, China

e-mail: zwcai@hkbu.edu.hk

G. Liu $\cdot$ M. Zheng $(\bowtie)$

State Key Laboratory of Environmental Chemistry and Ecotoxicology, Research Center for Eco-Environmental Sciences, Chinese Academy of Sciences, P.O. Box 2871, Beijing 100085, China

e-mail: zhengmh@rcees.ac.cn contaminations in soils from both thermal-related sources and evaporative emissions of technical PCN mixtures.

Keywords Persistent organic pollutants $\cdot$ Polychlorinated naphthalenes (PCNs) · PCDD/Fs · Polychlorinated biphenyls · Hong Kong · Stockholm Convention

\section{Introduction}

Polychlorinated dibenzo- $p$-dioxins (PCDDs), dibenzofurans (PCDFs) and polychlorinated biphenyl (PCBs) belong to the 12 initial persistent organic pollutants (POPs) listed under the Stockholm Convention on POPs. Polychlorinated naphthalenes (PCNs) display similar structure and toxic properties to those of PCDDs, PCDFs and PCBs (Blankenship et al. 2000; Villeneuve et al. 2000). PCNs have been suggested as a new candidate for a POPs under the Stockholm Convention on POPs (UNEP 2011). Investigation on the occurrence and profiles of PCNs in various environmental matrices began later than that of PCDDs, PCDFs and PCBs. Recent studies associated with PCN levels and profiles in various environmental and biota samples have attracted increasing attention (Lin et al. 2013; Hu et al. 2013a; Byer et al. 2013). For some typical contamination area or human samples, the contributions of PCNs in toxic equivalents (TEQ) were comparable to or even higher than those of PCDDs, PCDFs or PCBs (Park et al. 2010; Kannan et al. 1998, 2001). Furthermore, PCNs have been detected in various environmental and biota samples from many regions, including polar areas (Bidleman et al. 2010; Piazza et al. 2013).

Besides the historical manufacturing of PCNs and PCBs as a commercial mixture, PCNs, PCBs, PCDDs, PCDFs can also be unintentionally produced from various anthropogenic sources, and are often termed unintentional POPs (uPOPs) (Liu et al. 2009, 2010, 2012b, 2013). Industrial thermal 
sources including waste combustion and metal smelting were considered important sources of uPOPs (Hu et al. 2013b; Liu et al. 2012a, b, 2014; Falandysz 1998). Unintentional atmospheric emissions from anthropogenic sources have might become much more important sources of PCNs in air than before since the moratorium on manufacture and use of $\mathrm{PCNs}$ and PCBs in most countries (Liu et al. 2012b, 2014; Yamashita et al. 2003).

Hong Kong is situated on the southern coast of China. Although there are no intensive industrial activities in Hong Kong, occurrences of PCBs, PCDDs and PCDFs in various matrices including the environment, biota and human samples have been reported in many reports (Choi et al. 2008; Hedley et al. 2006; Kang et al. 2011; Kueh and Lam 2008; Louie and Sin 2003; Nelson et al. 2006; Wong et al. 2013). Specific investigations on PCN levels in the environmental matrices of Hong Kong have not been reported to our knowledge. PCNs have been proposed for inclusion in the annexes of the Stockholm Convention by the European Union (UNEP), signifying that there might be an increase in activities aimed at monitoring PCN levels in environmental and human samples at a global level. It is important to investigate the contamination levels of PCNs in environmental matrices in Hong Kong covered under the Stockholm Convention, which will provide useful data for understanding the contamination status of PCNs in Hong Kong.

Surface soils are not only sinks for POPs, but can also be secondary sources of POPs released into the environment (Liu et al. 2011). Harrad et al. (1994) noted that soils are an important reservoir for many POPs. For example, about $93 \%$ of the environmental burden of $\sum \mathrm{PCBs}$ in the UK was estimated to be associated with soils (Harrad et al. 1994). Investigations on the levels and profiles of POPs in surface soil are helpful for understanding their environmental contamination and risk exposure. In this preliminary investigation, surface soil samples from Hong Kong were collected and analyzed for PCNs using isotope dilution high-resolution gas chromatography combined with high-resolution mass spectrometer (HRGC/HRMS) techniques. PCBs, PCDDs and PCDFs in those samples were also analyzed with the HRGC/HRMS techniques with the aim of comparing the toxic contribution of PCNs with those of PCBs, PCDDs and PCDFs. To our knowledge, this is the first preliminary investigation on PCN levels in surface soil samples from Hong Kong, which will be helpful for understanding baseline levels of PCNs.

\section{Materials and methods}

Surface soil sampling

Hong Kong is located at the southeast tip of the China, with a total area of slightly over $1,100 \mathrm{~km}^{2}$. It is composed of Hong
Kong Island, Kowloon, the New Territories and a number of smaller islands. Hong Kong's climate is subtropical, tending towards temperate for nearly half the year. Most soils in Hong Kong are oxisols, typical of the humid tropics, characterized by strong weathering and leaching (Zhang et al. 2007). In this preliminary investigation, 14 surface soil samples $(0-10 \mathrm{~cm})$ were collected in 2013. Most of the samples were collected from urban parks. Each composite soil sample was comprised of six sub-samples from the sampling sites. All samples were tightly wrapped in aluminum foil and sealed in PE plastic bags. At the end of the sampling trip, the samples were immediately transferred to a refrigerator where they were stored until analysis. Sampling locations are described in Fig. 1.

\section{Chemical analysis of PCNs, PCBs, PCDDs and PCDFs}

PCNs were analyzed by isotope dilution HRGC/HRMS technique as described previously (Liu et al. 2011). The analysis of PCDD/Fs and PCBs was carried out based on the US EPA method 1613B and 1668A modifications, respectively. Briefly, the samples were spiked with known amounts of ${ }^{13} \mathrm{C}_{12}$-labeled PCDD/Fs, PCBs and PCN internal standards after grinding. The PCN internal standards (catalog no. ECN5102) were comprised of six congeners of ${ }^{13} \mathrm{C}_{10}$-CN-27, -42, $52,-67,-73$, and -75 . The spiked samples were extracted by accelerated solvent extraction (ASE) with a solution mixture of $n$-hexane and dichloromethane (1:1 in volume). The concentrated extract was purified by multilayer silica gel columns. PCDD/Fs, PCBs and PCNs were fractionated by basic aluminum columns. Finally, all the fractions were reduced to about $20 \mu \mathrm{l}$. Prior to injection, ${ }^{13} \mathrm{C}_{12}$-labeled injection standards were added into corresponding fractions for calculation of recoveries. The ${ }^{13} \mathrm{C}_{10}$-labeled CN-64 (catalog no. ECN-5260; Cambridge Isotope Laboratories) was used as the injection standard for calculating the recoveries of PCN internal standards. The analyses of PCNs, PCBs and PCDD/Fs were performed by an HRGC/HRMS. The MS was operated at $\geq 10,000$ resolution.

Congener peaks were identified based on retention time compared with available individual standards and ion ratios, and by considering the elution order on a DB-5 column. Peaks were quantified if target/qualifier ion ratios were within $15 \%$ of theoretical values. The limits of detection (LODs) in the surface soil samples ranged from 0.01 to $1.2 \mathrm{pg} \mathrm{g}^{-1}$ for $\mathrm{PCDD} / \mathrm{F}$ congeners, 0.02 to $3.2 \mathrm{pg} \mathrm{g}^{-1}$ for PCB congeners, and from 0.03 to $1.7 \mathrm{pg} \mathrm{g}^{-1}$ for PCN congeners. The recoveries of ${ }^{13} \mathrm{C}_{12}$-PCDD/Fs and ${ }^{13} \mathrm{C}_{12}$-PCBs internal standards were $39-127 \%$ and $43-139 \%$, respectively. The recoveries of ${ }^{13} \mathrm{C}_{10}-\mathrm{PCN}$ internal standards 


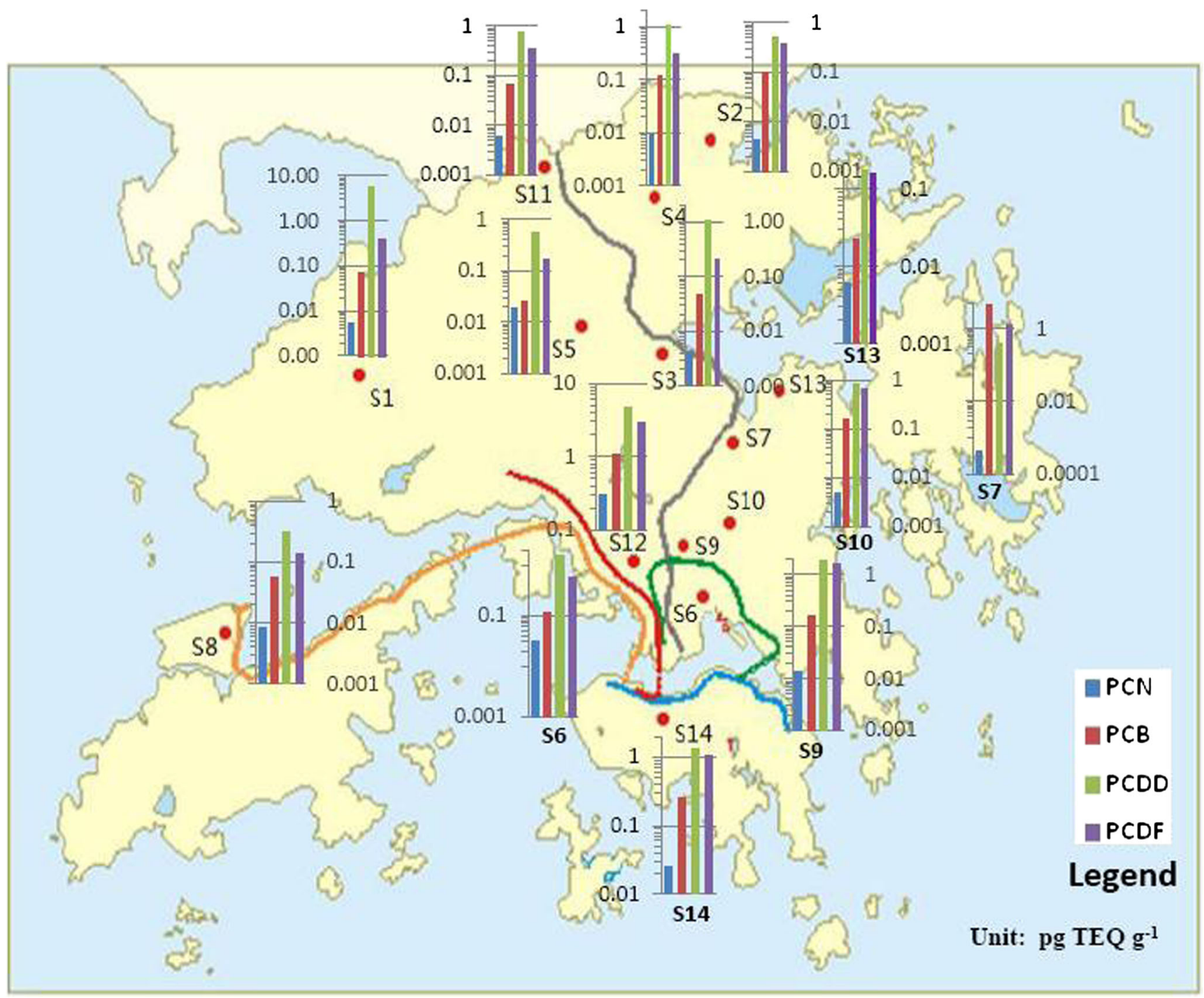

Fig. 1 Schematic of sampling sites and TEQs of PCNs, PCBs, PCDDs and PCDFs in surface soil samples

relative to labeled injection standards in the samples ranged from about 35 to $116 \%$.

\section{Results and discussion}

Concentrations of PCNs, PCBs, PCDDs and PCDFs

The concentrations of the contaminants in the surface soil samples were 35-883 $\mathrm{pg} \mathrm{g}^{-1}$ (average, 201; median, $94 \mathrm{pg} \mathrm{g}^{-1}$ ) for $\sum_{4-8} \mathrm{PCNs}, 151-99,100 \mathrm{pg} \mathrm{g}^{-1}$ (average, 9,990; median, $469 \mathrm{pg} \mathrm{g}^{-1}$ ) for $\sum_{4-8} \mathrm{PCBs}, 162-3,450 \mathrm{pg} \mathrm{g}^{-1}$ for 2,3,7,8-substituted PCDDs (average, 1110; median, $701 \mathrm{pg} \mathrm{g}^{-1}$ ), and 3-213 $\mathrm{pg} \mathrm{g}^{-1}$ for 2,3,7,8-substituted PCDFs (average, 28; median, 9). The concentrations of dioxin-like PCBs and indicator PCBs in the surface soil samples were 8-5,390 $\mathrm{pg} \mathrm{g}^{-1}$ (average, 567; median, $39 \mathrm{pg} \mathrm{g}^{-1}$ ), and 56-61,700 $\mathrm{pg} \mathrm{g}^{-1}$ (average, 5,950; median, $278 \mathrm{pg} \mathrm{g}^{-1}$ ), respectively. The concentrations of PCNs in the surface soil samples were obviously higher than those of 2,3,7,8-substituted PCDFs. The concentrations of PCNs in soil samples were obviously lower than those of 2,3,7,8-substituted PCDDs and PCBs.

Previous studies associated with the occurrences and profiles of PCBs, PCDDs and PCDFs in Hong Kong have focused on marine sediment, the atmosphere, biota and human breast milk (Choi et al. 2008; Hedley et al. 2006; Kang et al. 2011; Kueh and Lam 2008; Louie and Sin 2003; Nelson et al. 2006; Wong et al. 2013). There is still little available information on PCBs, PCDDs and PCDFs in the soils of Hong Kong. Zhang et al. (2007) determined the concentrations of PCBs in the soils of Hong Kong using a GC equipped with a ${ }^{63} \mathrm{Ni}$ electron capture detector- $\mu \mathrm{ECD}$. The concentrations of seven indicator PCB congeners ( $\left.\sum_{7} \mathrm{PCBs}\right)$ were $70-9,870 \mathrm{pg} \mathrm{g}^{-1}$. The average was $2,450 \mathrm{pg} \mathrm{g}^{-1}$, which was lower than the value 
of $5,947 \mathrm{pg} \mathrm{g}^{-1}$ reported in this study. The median value reported by Zhang et al. (2007) was $530 \mathrm{pg} \mathrm{g}^{-1}$, which was higher than the median value of $278 \mathrm{pg} \mathrm{g}^{-1}$ in this study.

Some publications have reported PCN levels in soil samples from many regions (Schuhmacher et al. 2004; Kannan et al. 1998; Krauss and Wilcke 2003; Meijer et al. 2001; Odabasi et al. 2010; Wang et al. 2012; Wyrzykowska et al. 2007). Table 1 summarizes the concentration of PCNs in soil samples from different areas. The PCN levels in Hong Kong soil samples were comparable to those of other urban soils, but were lower than those of industrial contamination sites. The comparison of PCN levels in Hong Kong soils with those of other regions, as well as the comparison with levels of dioxins and PCBs in Hong Kong soils, indicated a relatively low contamination status for PCNs in Hong Kong soil samples.

TEQs of PCNs and its comparison with PCBs, PCDDs and PCDFs

PCNs display similar toxic mechanisms to dioxins, inducing aryl hydrocarbon receptor (AhR) mediated responses, and are often referred to as dioxin-like compounds (Blankenship et al. 2000; Villeneuve et al. 2000). Although there are currently no internationally authorized toxic equivalency factor (TEF) schemes for PCN congeners, many studies have been performed to evaluate the TEF for individual PCN congeners relative to 2,3,7,8-tetrachlorodibenzo- $p$-dioxin $(2,3,7,8$ TCDD) (Hanberg et al. 1990; Villeneuve et al. 2000; Blankenship et al. 2000; Behnisch et al. 2003; Kannan et al. 2000). Some TEFs for individual PCN congeners have been proposed and used to evaluate the toxicities of PCNs. The TEFs of several PCN congeners relative to 2,3,7,8-TCDD have been summarized and reported by Noma et al. (2004). These estimated TEFs ranged from $1.8 \times 10^{-8}$ to $3.0 \times 10^{-3}$, and the TEFs of CN66/67, CN64/68, CN69, CN63, CN70, and CN73 were over $1.0 \times 10^{-3}$. Falandysz et al. (2013) recently evaluated and updated the relative potency factors of PCN congeners relative to 2,3,7,8-TCDD. In this study, the toxic equivalent (TEQ) of PCNs were calculated according to the TEFs of PCN congeners relative to 2,3,7,8-TCDD obtained by in vitro assays.

The TEQs of PCBs, PCDDs and PCDFs were calculated using the TEF of congeners suggested by the World Health Organization (Van den Berg et al. 1998). The TEQs of the investigated contaminants in the soil samples were 0.18

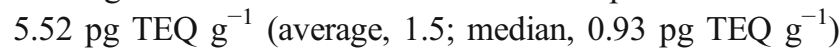
for PCDDs, 0.14-2.89 $\mathrm{pg}^{\mathrm{T}}$ TEQ $\mathrm{g}^{-1}$ (average, 0.73; median,

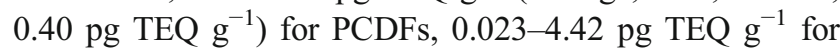

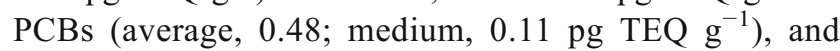
0.0004-0.25 pg TEQ $\mathrm{g}^{-1}$ for PCNs (average. 0.02; medium, $0.003 \mathrm{pg}^{\mathrm{T}} \mathrm{TEQ} \mathrm{g}^{-1}$ ). The TEQs of PCBs, PCDDs and PCDFs in Hong Kong soil samples in this study were comparable to other urban soils (Cai et al. 2008; Wang et al. 2008). The TEQs of PCNs, PCBs, PCDDs and PCDFs, and their distribution and comparison in soil samples are shown in Fig. 1. The TEQs of PCDDs were highest for most of the samples, followed by PCDFs. The TEQs of PCNs were the lowest. The TEQs of PCBs were lower than those of PCDFs, but higher than those of PCNs.

The contributions of PCNs, PCBs, PCDDs and PCDFs to their sum TEQs were calculated in this study. The most important contributor to the sum TEQ was PCDDs, accounting for an average value of $59 \%$ of the total TEQs, followed by PCDFs with an average of $29 \%$. The average contribution

Table 1 Concentrations of PCNs in soil samples from Hong Kong compared with levels found in other areas

\begin{tabular}{|c|c|c|c|c|c|c|c|}
\hline \multirow[t]{2}{*}{ Location } & \multirow[t]{2}{*}{ Samples } & \multirow{2}{*}{$\begin{array}{l}\text { Sampling } \\
\text { year }\end{array}$} & \multicolumn{2}{|c|}{ Concentration ( $\mathrm{pg} \mathrm{g}^{-1}$ ) } & \multirow[t]{2}{*}{ Homolog } & \multirow{2}{*}{$\begin{array}{l}\text { Analytical } \\
\text { method }\end{array}$} & \multirow[t]{2}{*}{ Reference } \\
\hline & & & Range & Average & & & \\
\hline Tarragona, Catalonia, Spain & Industrial site soil & 2002 & $70-121$ & 95 & $4-8$ & HRGC/HRMS & (Schuhmacher et al. 2004) \\
\hline Tarragona, Catalonia, Spain & Urban soil & 2002 & 180 & & $4-8$ & HRGC/HRMS & (Schuhmacher et al. 2004) \\
\hline Tarragona, Catalonia, Spain & Unpolluted site & 2002 & 32 & & $4-8$ & HRGC/HRMS & (Schuhmacher et al. 2004) \\
\hline Brunswick, GA & Industrial site & 1996 & & $17,900,000$ & $3-8$ & GC/MS & (Kannan et al. 1998) \\
\hline Bayreuth, Bavaria, Germany & Urban soils & & $<100-15,400$ & & $2-8$ & GC/MS & (Krauss and Wilcke 2003) \\
\hline Bayreuth, Bavaria, Germany & Industrial site soil & & $670-15,000$ & & $2-8$ & GC/MS & (Krauss and Wilcke 2003) \\
\hline Bayreuth, Bavaria, Germany & Rural soils & & $<100-820$ & & $2-8$ & GC/MS & (Krauss and Wilcke 2003) \\
\hline London, UK & Agricultural soil & 1986 & & 320 & $3-7$ & GC/MS & (Meijer et al. 2001) \\
\hline $\begin{array}{l}\text { Hatay and Iskenderun, } \\
\text { Turkey }\end{array}$ & Industrial site soil & 2008 & & 280,000 & $3-8$ & GC/MS & (Odabasi et al. 2010) \\
\hline Poland & Agricultural soil & 2002 & & $350-1,100$ & $3-8$ & HRGC/HRMS & (Wyrzykowska et al. 2007) \\
\hline Pearl River Delta, China & Surface soil & 2009 & & 59.9 & $4-6$ & GC-ECNI-MS & (Wang et al. 2012) \\
\hline Shanxi province, China & Surface soil & 2009 & $45-414$ & 172 & $1-8$ & HRGC/HRMS & (Liu et al. 2011) \\
\hline Hong Kong & Surface soil & 2013 & $34-883$ & 201 & $4-8$ & HRGC/HRMS & This work \\
\hline
\end{tabular}


of PCBs to the sum TEQ was $11 \%$. The average fraction of PCN TEQ in the sum TEQ of PCNs, PCBs, PCDDs and $P C D F$ s was only around $1 \%$. This indicated very low TEQ contributions from PCNs in Hong Kong surface soils compared with those of PCBs, PCDDs and PCDFs.

Congener profiles of PCNs, PCBs, PCDDs and PCDFs, and possible sources of $\mathrm{PCNs}$

The congener profiles of PCDDs and PCDFs are presented in Fig. 2. OCDD was the most dominant congener in PCDDs, followed by 1,2,3,4,6,7,8-HpCDD. OCDF and 1,2,3,4,6,7,8$\mathrm{HpCDF}$ were the dominant congeners in PCDFs. The congener profiles of dl-PCBs and indicator PCBs are presented in Fig. 3. PCB-118 was the dominant congener out of $12 \mathrm{dl}-$ PCB congeners, followed by PCB-105 and PCB- 156 . The concentration of PCB-126 among the 12 dl-PCB congeners was relatively low. However, the contributions of PCB-126 to the TEQs of dl-PCBs were significant owing to its higher TEF compared with the other dl-PCB congeners. The four PCB congener fractions PCB-28, PCB-138, PCB-153 and PCB-180 were obviously larger than those of PCB-52 and PCB-101.

The concentration of each $\mathrm{PCN}$ congener was expressed as a fraction of the corresponding homolog concentration. This normalization permitted a clear comparison of congener profiles in corresponding homologs (Liu et al. 2012a). The profiles of $\mathrm{PCN}$ congeners relative to tetraCN, pentaCN, hexaand hepta-CN homologs are shown in Fig. 4. In Fig. 4a, it can be seen that congeners of $\mathrm{CN} 33 / 34 / 37, \mathrm{CN} 45 / 36$ and CN38/40 were much more abundant than others in tetraCN. For congeners in pentaCN, CN52/60, CN51 and CN59 were dominant. For the hexaCN homolog, CN66/67, CN69 and
CN71/72 dominated over other congeners. The fractions of CN73 were comparable to those of CN74.

Congener profiles of PCNs could provide helpful information for speculating on their possible sources including emissions from thermal-related industries, or evaporative emissions of historical uses of industrial chemicals (such as Halowaxes). For example, Hanari et al. detail reported the profile of PCN congeners in Halowaxes 1001 and 1014 (Hanari et al. 2013). For tetraCN homolog, CN38 and CN46 were the most dominant congeners, and CN59 was the most abundant congener in pentaCN homolog. Several markers have also been suggested for identifying the sources of PCNs (Wyrzykowska et al. 2009; Orlikowska et al. 2009; Helm and Bidleman 2003). Wyrzykowska et al. (2009) and Orlikowska et al. (2009) reported the homolog and congener profiles of PCNs from household combustions and identifying the possible sources of PCNs in environmental and biota samples by pricinpal component analysis (Orlikowska et al. 2009; Wyrzykowska et al. 2009). Helm et al. evaluated the contribution of combustion related sources to the air contamination of PCN in Toronto, Canada, by using CN52/60, CN54, CN66/67 as the combustion markers (Helm and Bidleman 2003). Furthermore, the dominance of CN52/60 and CN50 has been reported for thermal-related processes (Schneider et al. 1998). Congeners composed of CN54 and CN66/67 are the most popular and relatively abundant indicators for waste incinerations (Meijer et al. 2001). In this study, CN52/60 and CN66/67, indicating combustion or other thermal-related sources, were dominant in the soil samples. This indicated the contribution of PCNs from combustion or other thermal related sources. The congeners of $\mathrm{CN} 38$ and CN59 indicating the possible release from Halowaxes were also relatively abundant in tetra- and penta-homologs in soils samples, which indicating the possible occurrence of PCNs
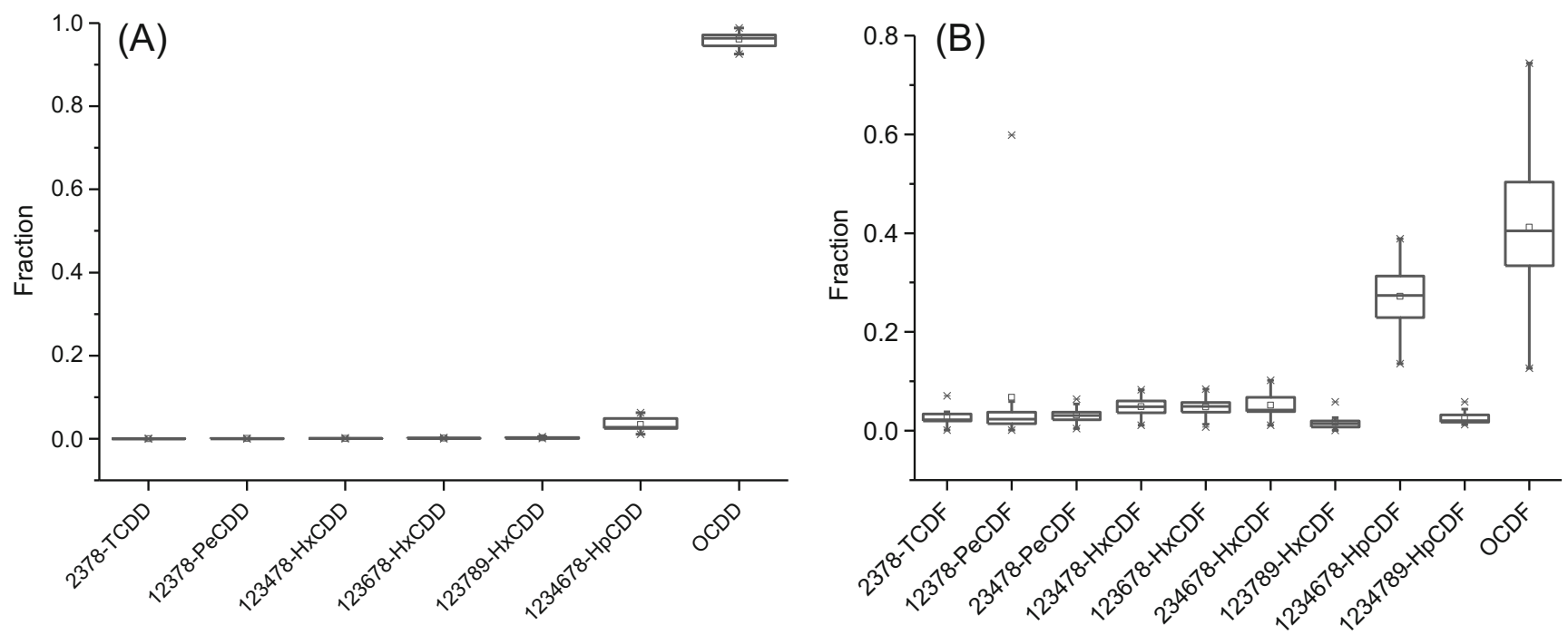

Fig. 2 Congener profiles of PCDDs (a) and PCDFs (b) in surface soil samples 

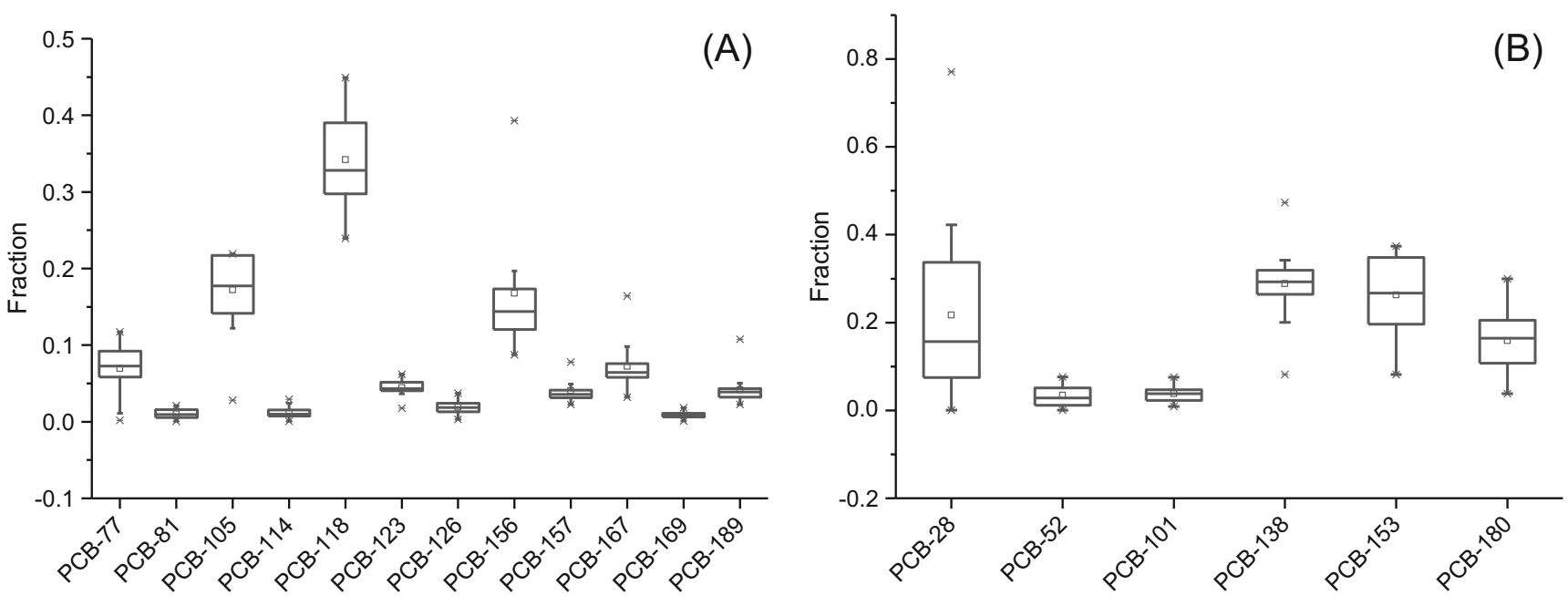

Fig. 3 Congener profiles of dl-PCBs (a) and indicator PCBs (b) in surface soil samples

from evaporative emissions of technical PCN formulations. The ratios of $\mathrm{CN} 73$ to $\mathrm{CN} 74\left(R_{\mathrm{CN} 73 / \mathrm{CN} 74}\right)$ vary in different source samples, with values far lower than one $(0.2-0.4)$ in Halowaxes (Noma et al. 2004) and markedly higher than one (2-25, with average of 5.7) in stack gases or fly ash samples collected from thermal-related sources (Liu et al. 2014). In the soil samples, fractions of CN73 were comparable to those of CN74. This phenomenon might signify the mixed effect of two types of sources: thermal-related sources, and evaporative emissions of technical PCN mixtures (such as Halowaxes).

The contamination levels of PCNs relative to those of PCBs $\left(\sum \mathrm{PCN} / \sum \mathrm{PCB}\right)$ have been used to speculate on the sources of PCNs in the atmosphere (Harner et al. 2000). It was suggested that a ratio of $\sum \mathrm{PCNs} / \sum \mathrm{PCBs}$ from 0.2 to 0.25 denotes the background levels of PCNs in the air, and a ratio $>0.25$ indicates "non-diffuse" or "point sources". In this study, the $\sum \mathrm{PCNs} / \sum \mathrm{PCBs}$ ratios in soil samples were also determined, and the ratios of $\sum \mathrm{PCNs} / \sum \mathrm{PCBs}$ were below 0.20 for most of those samples with an average of 0.23 . The PCN contamination in Hong Kong surface soils was regarded as background levels of PCN without intensive "point sources". Long range input of PCNs from thermal-related sources and evaporative emissions of technical PCN mixtures appear to be the sources of PCNs in Hong Kong soils.

\section{Conclusions}

PCN levels in surface soils samples from Hong Kong were determined by isotope dilution HRGC/HRMS techniques, and were compared with those of dioxins and PCBs in this preliminary study. The concentrations and TEQs of PCNs in the soil samples were far lower than those of dioxins and PCBs, which indicates that PCNs should not be the current priority POPs compared with dioxins and PCBs in Hong Kong surface soils. PCDDs were the most important contributor to the sum of TEQs of PCNs, PCBs, PCDDs and PCDFs. OCDD and PCB-118 were the most dominant congeners in seventeen 2,3,7,8-substituted PCDD/F and 12 dl-PCB congeners, respectively. According to the congener profiles of PCNs, it was speculated that the contribution of PCN contaminations in Hong Kong soils come from long range input including
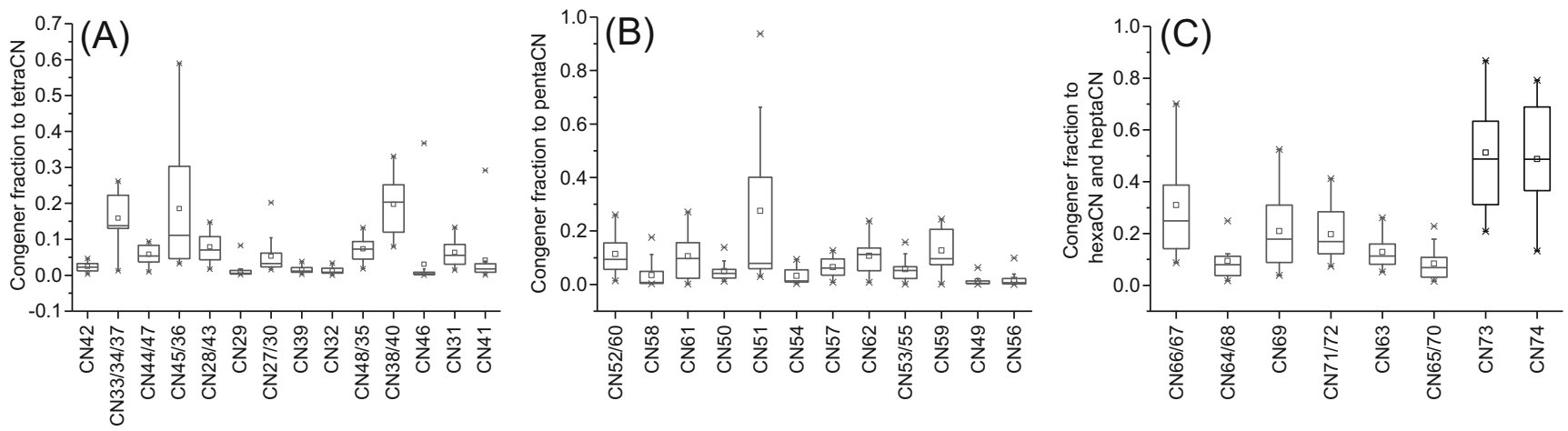

Fig. 4 Profile of PCN congeners relative to corresponding tetraCN (a), pentaCN (b), hexa- and hepta-CN (c) homologs 
both thermal-related sources and evaporative emissions of technical PCNs mixtures (such as Halowaxes).

Acknowledgments We gratefully acknowledge support from the Hong Kong Scholars Program (XJ2012055) and National Natural Science Foundation of China (No. 21361140359). We also appreciate the assistance of Dr. J. Shi and other colleagues during sample collections.

\section{References}

Behnisch PA, Hosoe K, Sakai S (2003) Brominated dioxin-like compounds: in vitro assessment in comparison to classical dioxin-like compounds and other polyaromatic compounds. Environ Int 29(6): 861-877

Bidleman TF, Helm PA, Braune BM, Gabrielsen GW (2010) Polychlorinated naphthalenes in polar environments - a review. Sci Total Environ 408(15):2919-2935

Blankenship AL, Kannan K, Villalobos SA, Villeneuve DL, Falandysz J, Imagawa T, Jakobsson E, Giesy JP (2000) Relative potencies of individual polychlorinated naphthalenes and halowax mixtures to induce $\mathrm{Ah}$ receptor-mediated responses. Environ Sci Technol 34(15):3153-3158

Byer JD, Alaee M, Brown RS, Lebeuf M, Backus S, Keir M, Pacepavicius G, Casselman J, Belpaire C, Oliveira K, Verreault G, Hodson PV (2013) Spatial trends of dioxin-like compounds in Atlantic anguillid eels. Chemosphere 91(10):1439-1446

Cai QY, Mo CH, Wu QT, Katsoyiannis A, Zeng QY (2008) The status of soil contamination by semivolatile organic chemicals (SVOCs) in China: a review. Sci Total Environ 389(2-3):209-224

Choi MPK, Ho SKM, So BKL, Cai Z, Lau AKH, Wong MH (2008) $\mathrm{PCDD} / \mathrm{F}$ and dioxin-like PCB in Hong Kong air in relation to their regional transport in the Pearl River Delta region. Chemosphere 71(2):211-218

Falandysz J (1998) Polychlorinated naphthalenes: an environmental update. Environ Pollut 101(1):77-90

Falandysz J, Fernandes A, Gregoraszczuk E, Rose M (2013) Aryl hydrocarbon receptor mediated (dioxin-like) relative potency factors for chlornaphthalenes. Organohalogen Compd 75:336-338

Hanari N, Falandysz J, Nakano T, Petrick G, Yamashita N (2013) Separation of closely eluting chloronaphthalene congeners by twodimensional gas chromatography/quadrupole mass spectrometry: an advanced tool in the study and risk analysis of dioxin-like chloronaphthalenes. J Chromatogr A 1301:209-214

Hanberg A, Waern F, Asplund L, Haglund E, Safe S (1990) Swedish dioxin survey - determination of 2,3,7,8-TCDD toxic equivalent factors for some polychlorinated-biphenyls and naphthalenes using biological tests. Chemosphere 20(7-9):1161-1164

Harner T, Lee RGM, Jones KC (2000) Polychlorinated naphthalenes in the atmosphere of the United Kingdom. Environ Sci Technol 34(15):3137-3142

Harrad SJ, Sewart AP, Alcock R, Boumphrey R, Burnett V, Duartedavidson R, Halsall C, Sanders G, Waterhouse K, Wild SR, Jones KC (1994) Polychlorinated-biphenyls (PCBs) in the British environment - sinks, sources and temporal trends. Environ Pollut 85(2):131-146

Hedley AJ, Wong TW, Hui LL, Malisch R, Nelson EAS (2006) Breast milk dioxins in Hong Kong and Pearl River Delta. Environ Health Perspect 114(2):202-208

Helm PA, Bidleman TF (2003) Current combustion-related sources contribute to polychlorinated naphthalene and dioxin-like polychlorinated biphenyl levels and profiles in air in Toronto, Canada. Environ Sci Technol 37(6):1075-1082
Hu JC, Zheng MH, Liu WB, Li CL, Nie ZQ, Liu GR, Xiao K, Dong SJ (2013a) Occupational exposure to polychlorinated dibenzo- $p$-dioxins and dibenzofurans, dioxin-like polychlorinated biphenyls, and polychlorinated naphthalenes in workplaces of secondary nonferrous metallurgical facilities in China. Environ Sci Technol 47(14):7773-7779

Hu JC, Zheng MH, Liu WB, Li CL, Nie ZQ, Liu GR, Zhang B, Xiao K, Gao LR (2013b) Characterization of polychlorinated naphthalenes in stack gas emissions from waste incinerators. Environ Sci Pollut Res 20(5):2905-2911

Kang Y, Cheung KC, Cai ZW, Wong MH (2011) Chemical and bioanalytical characterization of dioxins in indoor dust in Hong Kong. Ecotoxicol Environ Saf 74(4):947-952

Kannan K, Imagawa T, Blankenship AL, Giesy JP (1998) Isomer-specific analysis and toxic evaluation of polychlorinated naphthalenes in soil, sediment, and biota collected near the site of a former chloralkali plant. Environ Sci Technol 32(17):2507-2514

Kannan K, Yamashita N, Imagawa T, Decoen W, Khim JS, Day RM, Summer CL, Giesy JP (2000) Polychlorinated naphthalenes and polychlorinated biphenyls in fishes from Michigan waters including the Great Lakes. Environ Sci Technol 34(4):566-572

Kannan K, Kober JL, Kang YS, Masunaga S, Nakanishi J, Ostaszewski A, Giesy JP (2001) Polychlorinated naphthalenes, biphenyls, dibenzo-p-dioxins, and dibenzofurans as well as polycyclic aromatic hydrocarbons and alkylphenols in sediment from the Detroit and Rouge Rivers, Michigan, USA. Environ Toxicol Chem 20(9):18781889

Krauss M, Wilcke W (2003) Polychlorinated naphthalenes in urban soils: analysis, concentrations, and relation to other persistent organic pollutants. Environ Pollut 122(1):75-89

Kueh CSW, Lam JYC (2008) Monitoring of toxic substances in the Hong Kong marine environment. Mar Pollut Bull 57(6-12):744-757

Lin Y, Zhao YF, Qiu XH, Ma J, Yang QY, Shao M, Zhu T (2013) Spatial distribution of polychlorinated naphthalenes in the atmosphere across North China based on gridded field observations. Environ Pollut 180:27-33

Liu GR, Zheng MH, Liu WB, Wang CZ, Zhang B, Gao LR, Su GJ, Xiao K, Lv P (2009) Atmospheric emission of PCDD/Fs, PCBs, hexachlorobenzene, and pentachlorobenzene from the coking industry. Environ Sci Technol 43(24):9196-9201

Liu GR, Zheng MH, Lv P, Liu WB, Wang CZ, Zhang B, Xiao K (2010) Estimation and characterization of polychlorinated naphthalene emission from coking industries. Environ Sci Technol 44(21): $8156-8161$

Liu GR, Cai MW, Zheng MH, Nie ZQ, Liu WB, Lv P, Su GJ, Gao LR, Xiao K (2011) Levels and profiles of unintentionally produced persistent organic pollutants in surface soils from Shanxi Province, China. Bull Environ Contam Toxicol 86(5):535-538

Liu GR, Zheng MH, Du B, Nie ZQ, Zhang B, Hu JC, Xiao K (2012a) Identification and characterization of the atmospheric emission of polychlorinated naphthalenes from electric arc furnaces. Environ Sci Pollut Res 19(8):3645-3650

Liu GR, Zheng MH, Du B, Nie ZQ, Zhang B, Liu WB, Li C, Hu JC (2012b) Atmospheric emission of polychlorinated naphthalenes from iron ore sintering processes. Chemosphere 89(4):467-472

Liu GR, Zheng MH, Cai MW, Nie ZQ, Zhang B, Liu WB, Du B, Dong SJ, Hu JC, Xiao K (2013) Atmospheric emission of polychlorinated biphenyls from multiple industrial thermal processes. Chemosphere 90(9):2453-2460

Liu GR, Cai ZW, Zheng MH (2014) Sources of unintentionally produced polychlorinated naphthalenes. Chemosphere 94:1-12

Louie PKK, Sin DWM (2003) A preliminary investigation of persistent organic pollutants in ambient air in Hong Kong. Chemosphere 52(9):1397-1403

Meijer SN, Harner T, Helm PA, Halsall CJ, Johnston AE, Jones KC (2001) Polychlorinated naphthalenes in UK soils: time trends, 
markers of source, and equilibrium status. Environ Sci Technol 35(21):4205-4213

Nelson EAS, Hui LL, Wong TW, Hedley AJ (2006) Demographic and lifestyle factors associated with dioxin-like activity (CALUX-TEQ) in human breast milk in Hong Kong. Environ Sci Technol 40(5): $1432-1438$

Noma Y, Yamamoto T, Sakai SI (2004) Congener-specific composition of polychlorinated naphthalenes, coplanar PCBs, dibenzo- $p$-dioxins, and dibenzofurans in the halowax series. Environ Sci Technol 38(6):1675-1680

Odabasi M, Bayram A, Elbir T, Seyfioglu R, Dumanoglu Y, Ornektekin S (2010) Investigation of soil concentrations of persistent organic pollutants, trace elements, and anions due to iron-steel plant emissions in an industrial region in Turkey. Water Air Soil Pollut 213(14):375-388

Orlikowska A, Hanari N, Wyrzykowska B, Bochentin I, Horii Y, Yamashita N, Falandysz J (2009) Airborne chloronaphthalenes in Scots pine needles of Poland. Chemosphere 75(9):1196-1205

Park H, Kang JH, Baek SY, Chang YS (2010) Relative importance of polychlorinated naphthalenes compared to dioxins, and polychlorinated biphenyls in human serum from Korea: contribution to TEQs and potential sources. Environ Pollut 158(5):1420-1427

Piazza R, Gambaro A, Argiriadis E, Vecchiato M, Zambon S, Cescon P, Barbante C (2013) Development of a method for simultaneous analysis of PCDDs, PCDFs, PCBs, PBDEs, PCNs and PAHs in Antarctic air. Anal Bioanal Chem 405(2-3):917-932

Schneider M, Stieglitz L, Will R, Zwick G (1998) Formation of polychlorinated naphthalenes on fly ash. Chemosphere 37(9-12): 2055-2070

Schuhmacher M, Nadal M, Domingo JL (2004) Levels of PCDD/Fs, PCBs, and PCNs in soils and vegetation in an area with chemical and petrochemical industries. Environ Sci Technol 38(7):19601969

UNEP Stockholm Convention on Persistent Organic Pollutants (2011). http://www.pops.int/

Van den Berg M, Birnbaum L, Bosveld ATC, Brunstrom B, Cook P, Feeley M, Giesy JP, Hanberg A, Hasegawa R, Kennedy SW, Kubiak
T, Larsen JC, van Leeuwen FXR, Liem AKD, Nolt C, Peterson RE, Poellinger L, Safe S, Schrenk D, Tillitt D, Tysklind M, Younes M, Waern F, Zacharewski T (1998) Toxic equivalency factors (TEFs) for PCBs, PCDDs, PCDFs for humans and wildlife. Environ Health Perspect 106(12):775-792

Villeneuve DL, Kannan K, Khim JS, Falandysz J, Nikiforov VA, Blankenship AL, Giesy JP (2000) Relative potencies of individual polychlorinated naphthalenes to induce dioxin-like responses in fish and mammalian in vitro bioassays. Arch Environ Contam Toxicol 39(3):273-281

Wang DG, Yang M, Jia HL, Zhou L, Li YF (2008) Levels, distributions and profiles of polychlorinated biphenyls in surface soils of Dalian, China. Chemosphere 73(1):38-42

Wang Y, Cheng ZN, Li J, Luo CL, Xu Y, Li QL, Liu X, Zhang G (2012) Polychlorinated naphthalenes (PCNs) in the surface soils of the Pearl River Delta, South China: distribution, sources, and air-soil exchange. Environ Pollut 170:1-7

Wong TW, Wong AHS, Nelson EAS, Qiu H, Ku SYK (2013) Levels of PCDDs, PCDFs, and dioxin-like PCBs in human milk among Hong Kong mothers. Sci Total Environ 463:1230-1238

Wyrzykowska B, Hanari N, Orlikowska A, Bochentin I, Rostkowski P, Falandysz J, Taniyasu S, Horii Y, Jiang QT, Yamashita N (2007) Polychlorinated biphenyls and -naphthalenes in pine needles and soil from Poland - concentrations and patterns in view of long-term environmental monitoring. Chemosphere 67(9):1877-1886

Wyrzykowska B, Hanari N, Orlikowska A, Yamashita N, Falandysz J (2009) Dioxin-like compound compositional profiles of furnace bottom ashes from household combustion in Poland and their possible associations with contamination status of agricultural soil and pine needles. Chemosphere 76(2):255-263

Yamashita N, Taniyasu S, Hanari N, Horii Y, Falandysz J (2003) Polychlorinated naphthalene contamination of some recently manufactured industrial products and commercial goods in Japan. J Environ Sci Health A 38(9):1745-1759

Zhang HB, Luo YM, Wong MH, Zhao QG, Zhang GL (2007) Concentrations and possible sources of polychlorinated biphenyls in the soils of Hong Kong. Geoderma 138(3-4):244-251 